\title{
PAPER
}

\section{CSF galanin and cognition after shunt surgery in normal pressure hydrocephalus}

\author{
M Mataró, M A Poca, M del Mar Matarín, R Catalan, J Sahuquillo, R Galard
}

J Neurol Neurosurg Psychiatry 2003;74:1272-1277

See end of article for authors' affiliations

.....................

Correspondence to:

Rosa Galard, Department

of Biochemistry,

Neuroendocrinology

Research Unit, Vall

d'Hebron University

Hospital, Passeig de la Vall

d'Hebron 119-129.

08035 Barcelona, Spain

rgalard@hg.vhebron.es

Received

12 December 2002

In revised form

15 February 2003

Accepted l April 2003
$\mathrm{PH}$ ) is associated with injury to neurotransmitter Background: "Normal" pressure hydrocephalus (NPH) is associated with injury to neurotransmitter
and neuropeptide systems that recovers after surgery. This could be linked to changes in galanin, a neuropeptide with inhibitory effects on basal forebrain cognitive function.

Objective: To examine changes in CSF galanin concentrations in patients with normal pressure hydrocephalus undergoing shunt surgery, and to investigate the relation between these changes and cognitive functioning.

Methods: Eight patients underwent surgery for idiopathic normal pressure hydrocephalus. Lumbar CSF galanin determinations, cognitive status, and clinical status were quantified before operation and six months after. Cognition was assessed by an extensive battery of tests measuring attention, memory, speed of mental processing, visuospatial function, and frontal lobe function.

Results: CSF galanin concentration decreased after surgery. This reduction correlated with improved clinical and cognitive functioning, specifically with attention and visuomotor speed, visuoconstructive and frontal functioning, and clinical status according to the NPH scale, including the sphincter and cognitive components.

Conclusions: The cognitive and clinical improvement after shunt implantation correlated with CSF galanin levels, suggesting that the distribution or function of this agent involves cerebral structures that have some potential for recovery. In this study, galanin was related to several cognitive functions that may be associated with the fronto-subcortical deficits underlying cognitive dysfunction in normal pressure hydrocephalus.
$\mathrm{T}$ his study is a continuation of previous work investigating alterations in cerebrospinal fluid (CSF) neuropeptides involved in the modulation of cognitive processes in patients affected by dementia. In our earlier studies we determined CSF concentrations of cognition related neuropeptides in patients with Alzheimer's type dementia, multi-infarct dementia, and dementia related to normal pressure hydrocephalus compared with normal subjects. ${ }^{1-3}$ Our overall findings, together with the experience of other investigators in this field, ${ }^{4-6}$ suggest that dementias of diverse aetiology show similar CSF neuropeptide alterations, and that it is unlikely that specific neuropeptide markers will be found that can differentiate among the various dementias. Nevertheless, these determinations are useful for studying the brain dysfunction and damage that occur in several dementia types.

Cognitive impairment together with gait disturbances and urinary incontinence are common and important consequences of normal pressure hydrocephalus. At present, the only effective treatment for the progressive form of this disease is CSF shunt placement, which improves clinical symptoms in a substantial proportion of patients. By evaluating changes in CSF neuropeptide levels after shunting and correlating these with improvements in cognitive performance, it is possible to investigate the implications of specific neuropeptides for the cognitive symptoms of normal pressure hydrocephalus. The results obtained in the few studies undertaken along these lines ${ }^{78}$ showed significant increases in CSF neuropeptide levels after shunt surgery that correlated with clinical improvement; however, no correlations were found between cognitive improvement and the neuropeptide changes observed.

As we indicated in a previous study, ${ }^{8}$ the most plausible explanation for the persistence of neuropsychological impairment in the presence of improved neuropeptide levels is that irreversible neuronal functional injury occurs with the devel- opment of hydrocephalus. This probably takes place at the level of certain cortical synapses, as has been demonstrated in experimental studies. ${ }^{9}$

Galanin, a 29 amino acid peptide originally isolated from porcine intestine, ${ }^{10}$ is widely distributed in the mammalian central nervous system, ${ }^{112}$ where it is involved in many central functions, including those related to cognition. Several lines of evidence suggest that the important role of this peptide in attention and memory is based on its modulation of cholinergic basal forebrain activity. In rats, galanin inhibits hippocampal acetylcholine neurotransmission and impairs the performance of several attentional and memory tasks. ${ }^{13-23}$ In addition, galanin is overexpressed in the basal forebrain and cortex of patients with Alzheimer's disease. ${ }^{24-27}$ The cognition mediated function of galanin in forebrain pathways has led us to examine changes in CSF galanin levels in patients with normal pressure hydrocephalus undergoing shunt surgery and to investigate the relation between these changes and cognitive functioning, as determined by an extensive battery of neuropsychological tests. On the basis of the cognitive inhibitory actions of galanin, we hypothesised that galanin concentrations would decrease after shunt surgery and that the changes would be associated with neuropsychological improvement.

\section{METHODS}

Patients

Eight patients (three men and five women) with idiopathic normal pressure hydrocephalus were included in the study.

Abbreviations: AVLT, auditory-verbal learning test; NPH, normal pressure hydrocephalus; RDRS, rapid disability rating scale; TMT, trail making test; WAIS, Wechsler adult intelligence scale; WMS-R, Wechsler memory scale-R 
Table 1 Demographic and clinical characteristics of the sample

\begin{tabular}{|c|c|c|c|c|c|c|c|c|}
\hline & \multirow[b]{2}{*}{$\begin{array}{l}\text { Age } \\
\text { (years) }\end{array}$} & \multirow[b]{2}{*}{ Sex } & \multirow[b]{2}{*}{ Type } & \multirow[b]{2}{*}{$\begin{array}{l}\text { CSF galanin }(\mathrm{pg} / \mathrm{ml}) \text { : } \\
\text { basal/6 } \mathrm{m}\end{array}$} & \multirow[b]{2}{*}{$\begin{array}{l}\mathrm{NPH} \text { scale: } \\
\text { basal/6 m }\end{array}$} & \multirow[b]{2}{*}{$\begin{array}{l}\text { Stein scale: } \\
\text { basal/6 } \mathrm{m}\end{array}$} & \multicolumn{2}{|c|}{ Percentage change in: } \\
\hline & & & & & & & Galanin & $\mathrm{NPH}$ \\
\hline 1 & 71 & $\mathrm{~F}$ & Idiopathic & $10.80 / 7.50$ & $8 / 14$ & $4 / 2$ & -30.6 & 75.0 \\
\hline 2 & 60 & M & Idiopathic & $14.30 / 8.60$ & $12 / 13$ & $2 / 3$ & -39.9 & 8.3 \\
\hline 3 & 79 & $\mathrm{~F}$ & Idiopathic & $16.90 / 14.30$ & $8 / 9$ & $4 / 3$ & -15.4 & 12.5 \\
\hline 4 & 73 & $\mathrm{~F}$ & Idiopathic & $8.90 / 2.00$ & $6 / 14$ & $4 / 2$ & -77.5 & 133.3 \\
\hline 5 & 79 & $M$ & Idiopathic & $11.90 / 2.00$ & $9 / 13$ & $3 / 1$ & -83.2 & 44.44 \\
\hline 6 & 75 & M & Idiopathic & $8.80 / 9.50$ & $7 / 7$ & $4 / 4$ & 8.0 & 0.00 \\
\hline 7 & 81 & M & Idiopathic & $14.20 / 11.30$ & $11 / 13$ & $3 / 1$ & -20.4 & 18.2 \\
\hline 8 & 69 & $\mathrm{~F}$ & Idiopathic & $12.70 / 14.90$ & $10 / 5$ & $4 / 4$ & 17.32 & -50.00 \\
\hline
\end{tabular}

CSF, cerebrospinal fluid; NPH, normal pressure hydrocephalus.

Their mean (SD) age was $73.4(6.8)$ years, range 60 to 81 . All patients had ventricular dilatation (Evan's index $>0.30$ ) and a history of gait disturbance, cognitive deficits, or sphincter dysfunction. The diagnosis of normal pressure hydrocephalus and the decision to instal a shunt were based on our protocol of the study and management of this syndrome, and included clinical features, neuroimaging, continuous intracranial pressure monitoring, and CSF dynamics. ${ }^{28}{ }^{29}$ All patients underwent surgery between February 1998 and June 1999 and were evaluated before and six months afterwards. The patients in our series had attended school for a mean (SD) period of 8.0 (8.2) years, range 0 to 23. Informed consent for all aspects of the study was obtained from each patient or relative. Table 1 summarises the patients' demographic and clinical characteristics.

A low pressure valve system was implanted in all the patients. According to mean intracranial pressure values, Evans' index, and cortical sulci size, a delta valve (performance level 0.5) with an incorporated antisiphon device (Medtronic PS Medical, Goleta, California, USA) was implanted in two of the eight patients, and a Hakim Medos valve with a closing pressure range of $40 \pm 10 \mathrm{~mm} \mathrm{H}_{2} \mathrm{O}$ (Medos SA, Johnson and Johnson, Le Locle, Switzerland) and with an in-line infraclavicular gravity compensating accessory (NMT Neurosciences Implants SA, Sophia Antipolis, France) in the remaining six patients.

\section{Cerebrospinal fluid samples and galanin assay}

Lumbar CSF samples $(10 \mathrm{ml})$ were taken before and six months after shunting. CSF was obtained between 8:00 and 10:00 am, after at least eight hours of fasting and bed rest. CSF was collected in plastic tubes containing trasylol (1000 $\mathrm{kIU} / \mathrm{ml}$ ) to prevent proteolysis, immediately frozen at $-20^{\circ} \mathrm{C}$, and stored at $-80^{\circ} \mathrm{C}$.

Immunoreactive galanin was measured by a competitive radioimmunoassay (RIA; Peninsula Laboratories, San Carlos, California, USA) after an extraction-concentration procedure. The peptide was extracted from CSF samples $(3 \mathrm{ml})$ by absorption into columns packed with octadecasilyl silica (C18sep-pak., Water Associates, Milford, Massachusetts, USA) as previously described in detail. ${ }^{1}$ The methanol elutes were dried under a nitrogen stream, the extracts were reconstituted with $300 \mu \mathrm{l}$ of RIA buffer, and $100 \mu \mathrm{l}$ of the dissolved extract were taken in duplicate for RIA. The RIA was performed according to the conditions described in the kit. Calculations to determine immunoreactive galanin concentrations $(\mathrm{pg} / \mathrm{ml})$ in the CSF samples corresponded to the volume extracted. The galanin antiserum provided showed $100 \%$ cross reaction with human galanin and no cross reaction with secretin, substance $\mathrm{P}$, insulin, vasoactive intestinal polypeptide, and PHM-27. The detection limit of the assay was $2 \mathrm{pg} /$ tube. The intra-assay coefficient of variation was $9.1 \%$. All samples were assayed in duplicate in the same run to avoid interassay variation.

\section{Neuropsychological assessment}

Eleven psychometric tests measuring attention, verbal and visual memory, speed of mental processing, visuospatial functioning, and frontal lobe functions, ${ }^{30}$ and four clinical and functional scales were administered to all patients before and six months after shunting by the same examiner, who was blind to the biochemical results. These included the following:

- Attention and memory: information and orientation subtest, mental control subtest, and visual reproduction I and II subtests of the Wechsler memory scale-R (WMS-R); memory span for digits subtest of the Wechsler adult intelligence scale (WAIS); and two alternate versions of the auditory-verbal learning test (AVLT);

- Frontal functions: trail making tests (TMT) A and B; word fluency ("FAS" and animals) conducted over one minute each; and Stroop test (a computerised version of the test in which mean time for correct responses in the interference condition are recorded);

- Perceptual functions: judgment of line orientation test and block design subtest of the WAIS;

- Psychomotor speed: Purdue pegboard test and simple reaction time (simple colour dots matching trial from the Stroop test);

- Clinical status and daily life activities:

- 1. The NPH scale (normal pressure hydrocephalus scale) ${ }^{28}$ which evaluates the three main parts of the normal pressure hydrocephalus syndrome: gait, cognitive function, and sphincter disturbances and ranges from a score of 3 (patient is not ambulatory, has severe dementia, and urinary and faecal incontinence) to 15 (normal gait, cognitive disturbances only found by specific tests, and no sphincter dysfunction).

- 2. The rapid disability rating scale (RDRS-2), ${ }^{31}$ which assesses the degree of disability and is composed of 18 items scored on a scale of 1 to 4; a global score of 18 indicates that the person is totally independent and a score of 72 , totally dependent.

- 3. The modified Stein and Langfit scale, ${ }^{32}$ including five grades, starting from grade 0 in which there is no neurological deficit and the patient is able to work or perform the same duties as before the disease, to grade $\mathrm{V}$, in which the patient is bedridden or vegetative without any spontaneous activity or verbal contact;

- 4. The informant's test, which registers functional behaviour changes as reported by a close relative. It consists of 17 items scored on a five point basis $(1$, much better; 2 , a bit better; 3 , no change; 4 , a bit worse; 5 , much worse).

\section{Statistical analysis}

Non-parametric tests were used for statistical analyses. These included the Wilcoxon matched pairs signed ranks test to 
Table 2 Preoperative and postoperative values of variables in the battery of neuropsychological tests and behavioural scales

\begin{tabular}{|c|c|c|c|c|c|c|c|c|}
\hline \multirow[b]{2}{*}{ Tests } & \multicolumn{3}{|c|}{ Preoperative } & \multicolumn{3}{|c|}{ Postoperative } & \multirow[b]{2}{*}{$\mathrm{p}$ Value } & \multirow[b]{2}{*}{$\%$ Change } \\
\hline & Median & $(I Q R)$ & $\mathrm{n}$ & Median & (IQR) & $\mathrm{n}$ & & \\
\hline \multicolumn{9}{|l|}{ Neuropsychological tests } \\
\hline \multicolumn{9}{|l|}{ Attention/memory } \\
\hline Information and orientation (WMS-R) & 9.5 & $(6.5)$ & 8 & 12.0 & $(2.8)$ & 8 & NS & 13.9 \\
\hline Mental control (WMS-R) & 2.0 & (6.0) & 8 & 4.0 & $(4.5)$ & 8 & NS & 64.6 \\
\hline Digit span forward (WAIS) & 4.0 & (3.0) & 7 & 4.0 & $(1.8)$ & 8 & NS & 26.2 \\
\hline Digit span backward (WAIS) & 2.0 & (1.0) & 7 & 3.0 & (1.0) & 8 & NS & 16.7 \\
\hline AVLT learning & 16.0 & $(19.5)$ & 8 & 27.0 & (16.8) & 8 & $<0.05$ & 41.5 \\
\hline AVLT delayed recall & 0.0 & (3.0) & 8 & 1.0 & $(4.3)$ & 8 & NS & 29.9 \\
\hline Visual reproduction I (WMS-R) & 12.0 & $(23.5)$ & 8 & 16.5 & (14.3) & 8 & NS & 66.9 \\
\hline Visual reproduction II (WMS-R) & 2.0 & $(7.8)$ & 8 & 5.0 & $(9.0)$ & 8 & NS & 32.4 \\
\hline \multicolumn{9}{|l|}{ Frontal } \\
\hline Trail making test $A$ (TMT-A) & 224.0 & $(290.0)$ & 7 & 89.0 & (115.0) & 7 & $<0.05$ & 25.0 \\
\hline Trail making test $\mathrm{B}$ (TMT-B) & 301.0 & (341.0) & 4 & 334.0 & (189.0) & 5 & NS & 29.6 \\
\hline Phonemic fluency (FAS) & 11.0 & $(17.0)$ & 8 & 14.5 & $(13.8)$ & 8 & NS & 98.1 \\
\hline Semantic fluency (animals) & 5.0 & $(9.0)$ & 8 & 7.5 & $(9.5)$ & 8 & NS & 37.7 \\
\hline Stroop test (mean) & 4008 & (6533) & 7 & 1976 & (2155) & 6 & NS & 28.3 \\
\hline \multicolumn{9}{|l|}{ Perceptual } \\
\hline Line orientation & 11.0 & (17.3) & 8 & 12.5 & (11.8) & 8 & NS & 112.3 \\
\hline Block design & 0.0 & $(5.8)$ & 8 & 4.5 & (3.5) & 8 & $<0.05$ & 127.0 \\
\hline \multicolumn{9}{|l|}{ Psychomotor speed } \\
\hline Pegboard right & 6.5 & $(4.5)$ & 6 & 8.5 & $(3.5)$ & 6 & $<0.05$ & 41.0 \\
\hline Pegboard left & 4.0 & $(5.5)$ & 6 & 7.0 & $(5.0)$ & 6 & NS & 26.2 \\
\hline Reaction time (mean) & 1875 & (2313) & 7 & 1560 & (1147) & 7 & NS & 25.3 \\
\hline \multicolumn{9}{|l|}{ Behavioural scales } \\
\hline $\mathrm{NPH}$ score & 8.5 & (3.5) & 8 & 13.0 & (6.3) & 8 & NS & 30.2 \\
\hline NPH gait evaluation & 2.5 & $(2.0)$ & 8 & 4.0 & $(2.8)$ & 8 & NS & 76.0 \\
\hline NPH cognitive functions & 3.0 & (1.8) & 8 & 4.0 & $(0.0)$ & 8 & NS & 25.0 \\
\hline NPH sphincter disturbances & 3.0 & (1.5) & 8 & 4.5 & $(3.8)$ & 8 & NS & 19.8 \\
\hline RDRS-2 & 34.5 & (11.5) & 8 & 30.0 & (13.3) & 8 & NS & 8.4 \\
\hline Stein and Langfit & 4.0 & (1.0) & 8 & 2.5 & $(2.5)$ & 8 & NS & 26.2 \\
\hline Informant's test & 76.0 & (16.0) & 8 & 45.0 & (19.0) & 8 & $<0.01$ & 36.1 \\
\hline
\end{tabular}

analyse preoperative and postoperative differences, and Spearman's rank correlation test to study the relation between neuropeptide concentrations and neuropsychological and behavioural functioning. In addition, we calculated the percentage of change between basal and postoperative conditions: [(postoperative - preoperative)/preoperative] $\times 100$. Significance was set at a probability $(\mathrm{p})$ value of 0.05 . Values are given as mean (SD) or median (interquartile range).

\section{RESULTS}

\section{Preoperative status}

Before treatment, all patients had abnormal gait according to the NPH scale: three had abnormal but stable gait, one was able to walk independently but was unstable or subject to falls, three were unable to walk without help, and one was unable to walk at all. Cognition (NPH scale) was also impaired in all cases: three had memory problems, three had significant memory problems and behaviour disturbances of varying severity, and two had severe dementia. Sphincter control was as follows: one had no sphincter disturbances, one had urinary urgency, four had sporadic urinary incontinence, one had continuous urinary incontinence, and one had urinary and faecal incontinence. Five patients were dependent on others for activities of daily living (Stein and Langfit's scale grade IV), and three required some help or supervision (grades II and III).

\section{Postoperative neuropsychological and functional changes}

According to the NPH scale, at six months after surgery six patients showed clinical improvement, five had improved gait, four had improved cognitive functioning, and four of the seven with sphincter abnormalities had also improved. Only two patients remained dependent for daily activities (Stein and Langfit's scale grade IV), four required some help or supervision (grade II and III), and two were able to carry out daily activities independently (grade I).

As can be seen in table 2, statistical comparisons between preoperative and postoperative neuropsychological performance showed significant improvement in verbal memory (AVLT learning), visuoconstructive functioning (block design), and psychomotor speed (TMT-A and pegboard right hand), and in a daily life activities scale (informant's test).

\section{Neuropeptide changes}

Mean CSF galanin concentration showed a statistically significant decrease from $12.3(2.8) \mathrm{pg} / \mathrm{ml}$ on preoperative analysis to $8.8(4.9) \mathrm{pg} / \mathrm{ml}$ at the six month assessment $(\mathrm{z}=-2.10 ; \mathrm{p}=0.036)$.

Relation between percentage change in galanin levels and neuropsychological changes following surgery

Decreases in CSF galanin were significantly related to improvement in several clinical and neuropsychological tests. The per cent changes in galanin concentrations correlated with changes in the NPH scale (overall: $r=-0.76, \mathrm{p}=0.028$; cognitive component: $r=-0.86, \mathrm{p}=0.006$; and sphincter subcomponent: $r=-0.80, \mathrm{p}=0.017)$; attention and frontal lobe functioning (digit span forward: $r=-0.82, \mathrm{p}=0.025$; trail making test A: $r=0.86, \mathrm{p}=0.014$; Stroop test: $r=0.94$, $\mathrm{p}=0.005$ ); visuospatial functioning (block design: $r=-0.86$, $\mathrm{p}=0.007$ ), and visuomotor speed (pegboard right: $r=-0.83$, 

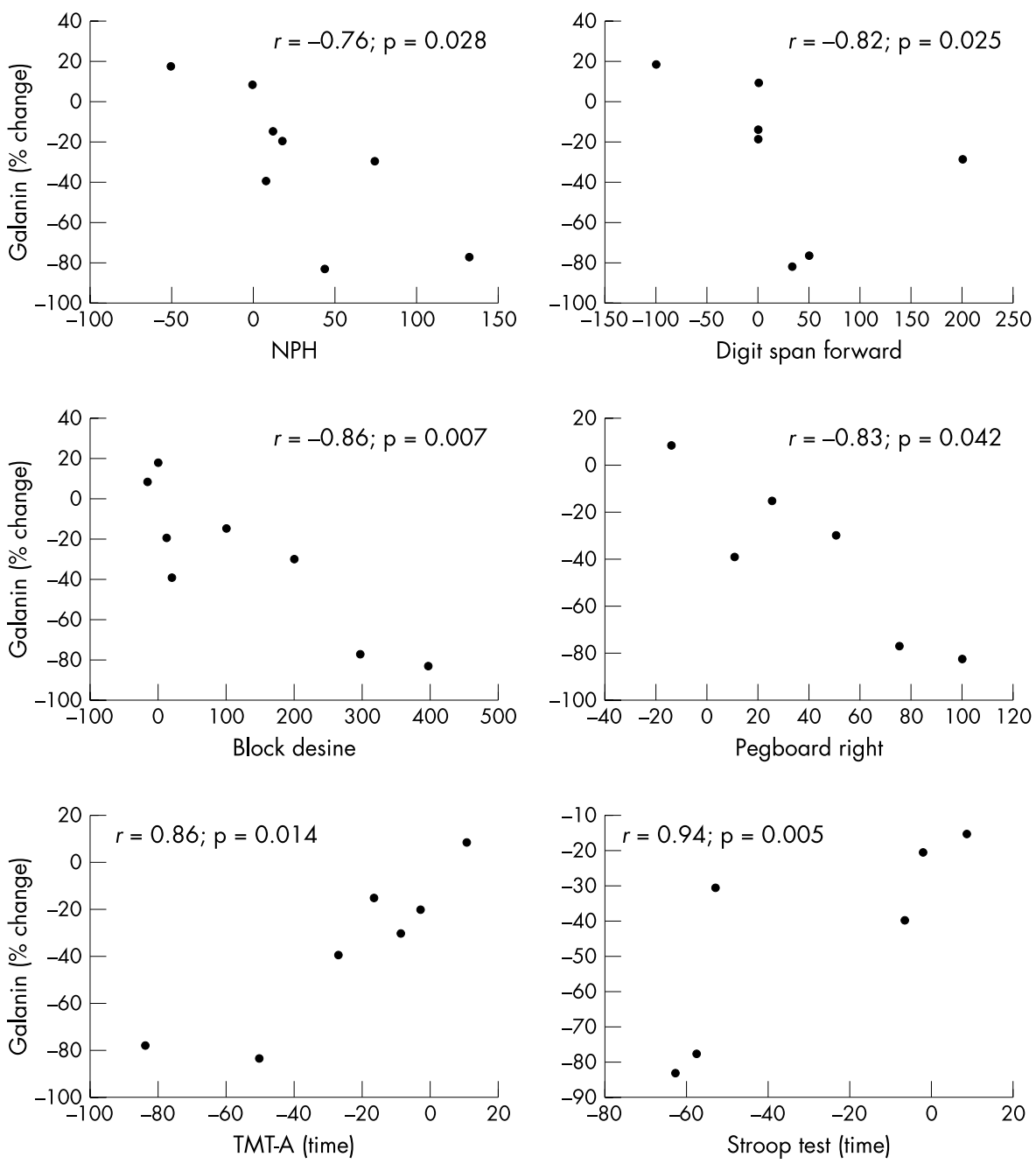

Figure 1 Scatterplots showing the relations between per cent change in galanin and per cent change in the neuropsychological tests.

$\mathrm{p}=0.042$ ) (fig 1). No relation was found between age, education, and duration and severity of normal pressure hydrocephalus, and post-shunt cognitive and neuropeptide changes.

\section{DISCUSSION}

The patients with idiopathic normal pressure hydrocephalus in our study had a significant postoperative reduction in CSF galanin concentrations. This finding agrees with previous research indicating the reversibility of some functionally injured neurotransmitter and neuropeptide systems following shunt surgery. ${ }^{783}$

Our results showed a correlation between improved functional and cognitive impairment after shunt implantation and CSF galanin changes. Postoperative decreases in galanin concentrations were related to improvements in attention and visuomotor speed, visuoconstructive and frontal functioning, and clinical status according to the NPH scale, including the cognitive and sphincter components. These good correlation results for galanin-in contrast to the poor correlations described for somatostatin, neuropeptide Y (NPY), corticotropin releasing factor (CRF), and vasoactive intestinal peptide (VIP) in similar studies ${ }^{78}$ - can be attributed to the different localisation of these peptides in the neocortex and the basal forebrain, together with the distinct type of neuronal injury resulting from abnormal intracranial pressure in these specific brain regions. Early studies investigating peptide regional brain distribution show that the cortex contains high concentrations of somatostatin, NPY, CRF, and VIP, and that the hippocampal formation is also very rich in these peptides. ${ }^{34-38}$
Similar work investigating the localisation of galanin immunoreactive neuronal structures in rat CNS showed a wide distribution of the peptide, including some areas of the cortex; however, the major galanin positive fibres were seen in the septal-basal forebrain, hypothalamus, pons/medulla, and spinal cord. Focusing on the basal forebrain system, galanin is co-localised with choline acetyltransferase in a subpopulation of neurones in the septal nucleus and diagonal band of the Broca area which project to the hippocampus (septohippocampal projection, through the fimbria-fornix), whereas the cholinergic neurones in the nucleus basalis of Meynert, innervating the cerebral cortex, do not contain detectable levels of the peptide. ${ }^{113940}$ The intraventricular location of the fimbriafornix and septum may make this pathway anatomically vulnerable at an early stage of hydrocephalus. However, these structures may have some potential to recover, as described experimentally. ${ }^{33}$

Recent studies in rats suggest a predominant inhibitory action of galanin on attention and working memory, ${ }^{41}{ }^{42}$ which is consistent with the role of the septohippocampal cholinergic system in processes involved in attention. ${ }^{43}$ In our study of patients with idiopathic normal pressure hydrocephalus, galanin was not only related to attention but also to speed, inhibition, and verbal fluency. All these functions, however, are part of the fronto-subcortical systems ${ }^{44}$ in which galanin may also play a role.

Thus in our study galanin was strongly related to several cognitive functions that may be associated with the frontal 
lobe deficits underlying cognitive dysfunction in normal pressure hydrocephalus. The neuropsychological profile in the dementia that accompanies normal pressure hydrocephalus has been documented in a small number of studies. Adams et al described the clinical picture of their patients as a disabling dementia with psychomotor retardation. ${ }^{45}$ The cardinal features, consistent with frontal symptoms, were slowness and paucity of thought and action and mild memory impairment. The condition was also characterised by a lack of spontaneity and initiative, faulty concentration, distractibility, lack of interest, apathy, and inertia. Other studies have confirmed this predominant involvement of frontal-subcortical functions. ${ }^{46-48}$ Also consistent with this neuropsychological pattern is the significant improvement in long term verbal memory, visuospatial functioning (block design subtest), and speed (TMT-A and pegboard right hand) in our patient sample following surgery. These tests are highly sensitive measures, capable of detecting small changes. In the remaining tests measuring the same functions, there was also an improvement following surgery although the differences did not reach statistical significance. The lack of statistically significant changes in all tests within the same domain could also reflect the fact that they assess different aspects of the domain.

\section{Conclusions}

In this report we have shown that the improvement in functional and intellectual impairment after shunt implantation is correlated with CSF galanin levels, which indicates that the distribution or function of this peptide involves cerebral structures that have some potential for recovery. The results of this preliminary work suggest that galanin is related to several cognitive functions, particularly fronto-subcortical function. It would be of particular interest to include this peptide in the development of new pharmacological strategies in the light of favourable results already obtained with the use of galanin antagonists in certain types of neurological impairment.

\section{ACKNOWLEDGEMENTS}

This study was partially supported by grants numbers FIS 99/0968 and $\mathrm{PR}(\mathrm{HG}) 50 / 2002$.

\section{Authors' affiliations}

M Mataró, M del Mar Matarín, Department of Psychiatry and Clinical Psychobiology, University of Barcelona, Barcelona Spain M A Poca, J Sahuquillo, Department of Neurosurgery, Vall d'Hebron University Hospital, Barcelona

R Catalan, R Galard, Department of Biochemistry, Neuroendocrinology Research Unit, Vall d'Hebron University Hospital

\section{Competing interests: none declared}

\section{REFERENCES}

1 Alom J, Galard R, Catalán R, et al. Cerebrospinal fluid neuropeptide Y in Alzheimer's disease. Eur Neurol 1990;30:207-10.

2 Molins A, Catalán R, Sahuquillo J, et al. Somatostatin cerebrospinal fluid levels in dementia. J Neurol 1991;238:168-70.

3 Catalán R, Sahuquillo J, Poca MA, et al. Neuropeptide Y cerebrospinal fluid levels in patients with normal pressure hydrocephalus syndrome. Biol Psychiatry 1994;36:61-3.

4 Wikkelsö C, Fahrenkrug J, Blomstrand C, et al. Dementia of different etiologies: vasoactive intestinal polypeptide in CSF. Neurology 1985;35:592-5

5 Heilig $M$, Sjogren M, Blennow K, et al. Cerebrospinal fluid neuropeptides in Alzheimer's disease and vascular dementia. Bio Psychiatry 1995:38:210-16.

6 Cramer H, Schaudt D, Rissler K, et al. Somatostatin-like immunoreactivity and substance-P-like immunoreactivity in the CSF of patients with senile dementia of Alzheimer type, multi-infarct syndrome and communicating hydrocephalus. J Neurol 1985;232:346-51.

7 Wikkelsö C, Ekman R, Westergren I, et al. Neuropeptides in cerebrospinal fluid in normal-pressure hydrocephalus and dementia. Eur Neurol 1991;31:88-93

8 Poca MA, Mataró M, Sahuquillo J, et al. Shunt related changes in somatostatin, neuropeptide $Y$ and corticotropin releasing factor concentrations in patients with normal pressure hydrocephalus. J Neurol Neurosurg Psychiatry 2001;70:298-304.
9 Miyazawa T, Sato K. Learning disability and impairment of synaptogenesis in HTX-rats with arrested shunt-dependent hydrocephalus. Childs Nerv Syst 1991;7:121-8

10 Tatemoto K, Rokaeus K, Jornvall H, et al. Galanin - a novel biologically active peptide from porcine intestine. FEBS Lett 1983;164:124-8.

11 Melander T, Hökfelt T, Rökaeus A. Distribution of galaninlike immunoreactivity in the rat central nervous system. J Comp Neurol 1986;248:475-517.

12 Perez SE, Wynick D, Steiner RA, et al. Distribution of galaninergic immunoreactivity in the brain of the mouse. J Comp Neurol 2001;434:158-85.

13 Mastropaolo J, Nadi NS, Ostrowski NL, et al. Galanin antagonizes acetylcholine on a memory task in basal forebrain-lesioned rats. Proc Nat Acad Sci USA 1988;85:9841-5.

14 Sundström E, Archer T, Melander T, et al. Galanin impairs acquisition but not retrieval of spatial memory in rats studied in the Morris swim maze. Neurosci Lett 1988:88:331-5.

15 Malin DH, Novy BJ, Lett-Brown AE, et al. Galanin attenuates retention of one-trial reward learning. Life Sci 1992;50:939-44.

16 Robinson JK, Crawley JN. Intraventricular galanin impairs delayed nonmatching-to-sample performance in rats. Behav Neurosci 1993:107:458-67.

17 Robinson JK, Crawley JN. Analysis of anatomical sites at which galanin impairs delayed nonmatching to sample in rats. Behav Neurosci 1994; 108:941-50.

18 Ukai $\mathbf{M}$, Miura M, Kameyama T. Effects of galanin on passive avoidance response, elevated plus-maze learning, and spontaneous alternation performance in mice. Peptides 1995:16:1283-6.

19 McDonald MP, Crawley JN. Galanin receptor antagonist M40 blocks galanin-induced choice accuracy deficits on a delayed nonmatching-to-position task. Behav Neurosci 1996;110:1025-32.

20 Ögren SO, Kehr J, Schött PA. Effects of ventral hippocampal galanin on spatial learning and on in vivo acetylcholine release in the rat. Neuroscience 1996:75:1127-40.

21 Schött PA, Bjelke B, Ögren SO. Distribution and kinetics of galanin infused into the ventral hippocampus of the rat: relationship to spatial learning. Neuroscience 1998;83:123-36.

22 McDonald MP. Willard LB, Wenk GL, et al. Coadministration of galanin antagonist M40 with a muscarinic $M 1$ agonist improves delayed nonmatching to position choice accuracy in rats with cholinergic lesions. J Neurosci 1998;18:5078-85

23 Gleason TC, Dreiling JL, Crawley JN. Rat strain differences in response to galanin on the Morris water task. Neuropeptides 1999;33:265-70.

24 Chan-Palay V. Galanin hyperinnervates surviving neurons of the human basal nucleus of Meynert in dementias of Alzheimer's and Parkinson's disease: a hypothesis for the role of galanin in accentuating cholinergic dysfunction in dementia. J Comp Neurol 1988;273:543-57.

25 Beal MF, MacGarvey U, Swartz KJ. Galanin immunoreactivity is increased in the nucleus basalis of Meynert in Alzheimer's disease. Ann Neurol 1990;28:157-61.

26 Mufson EJ, Cochran E, Benzing W, et al. Galaninergic innervation of the cholinergic vertical limb of the diagonal band (Ch2) and bed nucleus of the stria terminalis in aging, Alzheimer's disease and Down's syndrome. Dementia 1993:4:237-50.

27 Gabriel SM, Bierer LM, Davidson M, et al. Galanin-like immunoreactivity is increased in the postmortem cerebral cortex from patients with Alzheimer's disease. J Neurochem 1994;62:1516-23.

28 Sahuquillo J, Rubio E, Codina A, et al. Reappraisal of the intracranial pressure and cerebrospinal fluid dynamics in patients with the so-called "normal pressure hydrocephalus" syndrome. Acta Neurochir (Wien) $1991 ; 112: 50-61$

29 Poca MA, Sahuquillo J, Busto M, et al. Clinical management of patients with normal pressure hydrocephalus syndrome. Ann Psychiatry 1996:6:273-92.

30 Lezak M. Neuropsychological assessment, 3rd ed. New York: Oxford University Press, 1995

31 Linn MW, Linn BS. The rapid disability rating scale-2. J Am Geriatr Soc 1982;30:378-82.

32 Borgersen SE. Conductance to oufflow of CSF in normal pressure hydrocephalus. Acta Neurochir (Wien) 1984;71:1-45.

33 Tashiro Y, Drake JM. Reversibility of functionally injured neurotransmitter systems with shunt placement in hydrocephalic rats: implications for intellectual impairment in hydrocephalus. J Neurosurg 1998;88:709-17.

34 Emson PC, Fahrenkrug J, Spokes EG. Vasoactive intestinal polypeptide (VIP): distribution in normal human brain and in Huntington's disease. Brain Res 1979;173:174-8.

35 Skofitsch G. Jacobowitz DM. Immunohistochemical mapping of galanin-like neurons in the rat central nervous system. Peptides 1985;6:509-46.

36 Beal MF, Uhl G, Mazurek MF. Somatostatin in the central nervous system: physiology and pathological modifications. Prog Neurobiol 1986;27:63-100.

37 Gray TS, Morley JE. Neuropeptide Y: anatomical distribution and possible function in mammalian nervous system. Life $\mathrm{Sci}$ 1986;38:389-401.

38 Charlton BG, Ferrier IN, Perry RH. Distribution of corticotropin-releasing factor-like immunoreactivity in human brain. Neuropeptides 1987; 10:329-34

39 Melander T, Staines WA, Hökfelt T, et al. Galanin-like immunoreactivity in cholinergic neurons of the septum-basal forebrain complex projecting to the hippocampus of the rat. Brain Res 1985;360:130-8.

40 Senut MC, Menetrey D, Lamour Y. Cholinergic and peptidergic projections from the medial septum and the nucleus of the diagonal band 
of Broca to dorsal hippocampus, cingulate cortex and olfactory bulb: a combined wheatgerm agglutinin-apohorseradish peroxidase-gold immunohistochemical study. Neuroscience 1989;30:385-403.

41 Crawley JN, Wenk GL. Co-existence of galanin and acetylcholine: is galanin involved in memory processes and dementia? Trends Neurosci 1989:12:278-82

42 Crawley JN. Galanin-acetylcholine interactions: relevance to memory and Alzheimer's disease. Life Sci 1996;58:2185-99.

43 Miyamoto M, Kato J, Narumi S, et al. Characteristics of memory impairment following lesioning of the basal forebrain and medial septal nucleus in rats. Brain Res 1987:419:19-31.

44 Alexander GE, DeLong MR, Strick PL. Parallel organization of functionally segregated circuits linking basal ganglia and cortex. Annu Rev Neurosci 1986:9:357-81.
45 Adams RD, Fisher CM, Hakim S, et al. Symptomatic occult hydrocephalus with "normal" cerebrospinal fluid pressure. N Engl J Med 1965;273:117-26.

46 Caltagirone C, Gainotti G, Masullo C, et al. Neurophysiological study of normal pressure hydrocephalus. Acta Psychiatr Scand 1982;65:93-100.

47 Stambrook M, Cardoso E, Hawryluk GA, et al. Neuropsychological changes following the neurosurgical treatment of normal pressure hydrocephalus. J Clin Neuropsychol 1988;3:323-30.

48 Iddon JL, Pickard JD, Cross JJ, et al. Specific patterns of cognitive impairment in patients with idiopathic normal pressure hydrocephalus and Alzheimer's disease: a pilot study. J Neurol Neurosurg Psychiatry 1999;67:723-32.

\section{HISTORICAL NOTE}

\section{Charcot on "provoked trepidation", or clonus}

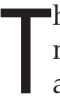
he classic signs of upper motor neurone lesions became recognised in the second half of the 19th century. Charcot and his colleagues first distinguished them from the flaccid weakness of poliomyelitis, posterior column lesions (locomotor ataxy), neuropathic, and myopathic lesions. The contributions of Erb, ${ }^{1}$ Marshall Hall, ${ }^{2}$ and Westphal ${ }^{3}$ to the related tendon reflexes are well know, but the origins of clonus are less clearly portrayed. The import of these signs can hardly be overestimated. In Charcot's lectures (references as in his text $)^{4}$ he said of clonus:

“. . known in France under the name of provoked trepidation, or provoked spinal epilepsy. German writers call it the foot-phenomenon (Fussphoenomen) or ankle clonus. But the discovery of this sign belongs to French clinical observers. Since 1863. . it has been practised daily in the wards of La Salpêtrière by M. Vulpian, by myself, and by our pupils."

“. . .it is habitually absent in the motor inability connected with locomotor ataxy, infantile spinal paralysis, and in other conditions of the same kind, whereas it is never wanting in paralysis of cerebral or spinal origin, in which contracture exists or tends to become established."

"The phenomenon may be described as follows. The paralysed lower limb of a hemiplegic patient is supported by placing one hand beneath the ham so that the patient's leg may hang loose and swing; if now, with the other hand, the point of the foot is suddenly raised, a series of shakes is at once provoked, which collectively constitute a kind of rhythmical movement or oscillatory trembling more or less regular and persistent. Spinal trepidation presents the more interest from the fact that, as a rule, no trace of it exists in the normal state. Thus Herr Berger, ${ }^{6}$ who has made some observations on the matter, only discovered it three times in 14000 apparently healthy subjects (mostly soldiers)."

"I must, however, repeat emphatically that, in the domain of pathology, this is not a constant phenomenon, since in certain spinal affections it is absent, whilst in others the rule is for it to be present. Briefly, it is one of the characteristic features of the group of spasmodic [Charcot often uses the term spasmodic for spastic] paralyses; and to this category belongs central hemiplegia with secondary degeneration of the pyramidal tract:"

"When late contracture has taken place, this phenomenon is nearly constant, but it frequently precedes the contracture by several weeks. In a patient, now an inmate in the infirmary of La Salpêtrière, it began to manifest its presence a week after the attack, and a fortnight later rigidity of the lower limb first made its appearance."

"In another patient, it did not appear until a month after the attack, and the muscular rigidity began to be evident in the course of the second month."

“M. Dejerine has recently pointed out that this symptom is occasionally present in both lower limbs, and we shall see that this is sometimes the case with contracture."

"In hemiplegic patients possessing some slight power of movement, this same trepidation which, in certain cases extends to the entire limb, may also manifest itself in consequence of a voluntary movement. The phenomenon in question is reflex, as I purpose to demonstrate at greater length on a subsequent occasion. . ."

"An analogous phenomenon is occasionally produced when the hand of a hemiplegic patient is suddenly lifted up by the tips of the fingers. Moreover, these patients, on raising the paralysed arm, often experience a trembling similar to that which occurs in the lower limb under like circumstances. But the wrist-phenomenon, provoked or spontaneous, is much more uncommon than the corresponding effect which we call the footphenomenon."

"These two signs, as we shall show, belong to the same category as those recently introduced into the semeiotics of spinal affections by Westphal, and afterwards by Erb, under the collective term of tendon-reflexes."

J M S Pearce

304 Beverley Road, Anlaby, Hull HU10 7BG, UK jmspearce@freenet.co.uk

\section{References}

1 Erb WH. Uber Sehnenreflexe bei gesunden und bei ruckenmarkskranken. Arch Psychiat Nervenkr 1875:5:792-802. [See also Gowers WR. Diagnosis of diseases of the brain and spinal cord. New York: Wm Wood \& Co, 1885:222-3.]

2 Pearce JMS. Notes on the life and work of Marshall Hall. Quart J Med 1997;90:801-3.

3 Westphal CF. Uber einige durch mechanische einwirkung auf sehnen und muskeln hervogebrachte bewegungs-erscheinungen. Arch Psyciat Nervenkr 1875;5:803-34.

4 Charcot JM. Lectures on the localisation of cerebral and spinal diseases (trans and ed WB Hadden). London: The New Sydenham Society, 1883:248-9.

5 Dubois OE, These de Paris,' 1868. Cited by Charcot, ref 4 .

6 Berger. Arch d Heilk, ${ }^{1}$ 1879, No. 4. Cited by Charcot, ref 4. 